\title{
Extensão rural e desenvolvimento com sustentabilidade cultural: o Ponto de Cultura no Sertão Pernambucano (Brasil)
}

Rural extension and development with cultural sustentability: the point of the culture on the arid and remote interior of Pernambuco (Brazil)

L'extension rurale et le développement avec la sustentabilité culturelle: le point de culture dans le désert de Pernambuco (Brésil)

Extensión rural y desarrollo con sostenimiento cultural: el Punto de Cultura en Sertão

Pernambucano (Brasil)

\author{
Camila Loureiro* \\ Angelo Brás F. Callou**
}

Recebido em 20/12/2006; revisado e aprovado em 29/3/2007; aceito em 20/7/2007

\begin{abstract}
Resumo: Analisa-se no presente artigo as contribuições do Projeto Estação da Cultura: o Ponto de Cultura no Sertão Pernambucano, selecionado pelo Programa Cultura Viva, do Governo Federal para o desenvolvimento local de Arcoverde, em Pernambuco. Especificamente, pretende-se observar as possibilidades de "sustentabilidade cultural", a partir da implantação da Estação da Cultura nesta cidade. Neste trabalho, ressalta-se a importância de centralizar a sustentabilidade cultural como premissa para o desenvolvimento local, vislumbrando nas pessoas dessas comunidades como principais atores nesse processo.
\end{abstract}

Palavras-chave: extensão rural; desenvolvimento local; sustentabilidade cultural.

Abstract:. In this essay we analise the contributions of the "Projeto Estação da Cultura : o Ponto de Cultura no Sertão Pernambucano", selected by "Programa Cultura Viva", from Federal Government for the local development of Arcoverde, in Pernambuco. Specifically, we intend to observe the possibilities of "Cultural supports", starting from the Estação Cultura implementation at the city. In this work, it is spotted the importance of to centralize the "cultural supports" as basis for the local development, looking to the people of these towns as the stars of these process.

Key words: rural extention; local development; cultural support.

Résumé: Cet article analyse les contribuitions du Projet de la Station de la Culture dans le désert du Pernambuco, sélectionné par le Programme Cultura Viva (Culture Vive) , du Governement Fédéral pour le développement local de Arcoverde, à Pernambuco. Notamment, on espére étudier les possibilités de sustentabilité culturelle, à partir de l'implantation de la Station de la Culture dans cette ville. On accentue l'importance de centraliser la sustentabilité culturelle comme prémisse pour le développement local. Alors, les habitants de ces communautés sont primordiaux dans ce procès.

Mots-clés: extension rurale; développement local; sustentabilité culturelle.

Resumen: Se analiza en el presente artículo las contribuciones del Proyecto Estación de la Cultura: el Punto de Cultura en Sertão Pernambucano, seleccionado por el Programa Cultura Viva, del Gobierno Federal para el desarrollo local de Arcoverde, en Pernambuco. Específicamente, se pretende observar las posibilidades de "sostenimiento cultural", a partir de la implantación de la Estación de Cultura en esta ciudad. En este trabajo, sobresale la importancia de centralizar el sostenimiento cultural como premisa para el desarrollo local, vislumbrando en las personas de esas comunidades como principales actores en ese proceso.

Palabras clave: extensión rural; desarrollo local; sostenimiento cultural.

\section{Introdução}

A temática da comunicação e cultura e do desenvolvimento local nos estudos de Extensão Rural surge a partir dos anos 90. Expande-se, assim, com o advento dos processos de globalização, da degradação ambiental, dos avanços tecnológicos emergentes, dos estudos de recepção latino-americanos (desenvolvidos a partir do cultural studies ingleses) e das novas concepções sobre o ru- ral brasileiro (CALLOU, 2002). Esse assunto é abordado pela primeira vez no artigo Desafios da Comunicação Rural em Tempo de Desenvolvimento Local, em 1995 (CALLOU; TAUK SANTOS, 1995). A partir daí, as antigas abordagens de Extensão Rural, que oscilavam entre o paradigma funcionalista modernizador e as teorias de participação paulofreirianas, "não servem mais para explicar o velho objeto" (TAUK SANTOS, 2000, p. 299). Contemporaneizar a Exten-

\footnotetext{
* Mestre em Extensão Rural e Desenvolvimento Local pela Universidade Federal Rural de Pernambuco, amiaaa@hotmail.com.

** Professor Titular da Universidade Federal Rural de Pernambuco, peixes@elogica.com.br.
} 
são Rural significa, para Tauk Santos (2000), enfocar o desenvolvimento local numa tentativa de promover mudanças em prol das culturas populares.

Os estudos culturais latino-americanos da comunicação, sobretudo, pela via dos estudos de recepção, propostos por Jesús Martín-Barbero e Néstor García Canclini, trouxeram novos aspectos teóricos para instrumentalizar a Extensão Rural na sua relação com o desenvolvimento local (CALLOU, 2004). Isso ocorre particularmente a partir da tese de doutoramento de Tauk Santos (1994) sobre a participação de pequenos produtores no Programa de Desenvolvimento Rural do Serviço de Tecnologias Alternativas (SERTA). Se, até então, os estudos de recepção, ainda que escassos, estavam voltados majoritariamente para a recepção de produtos midiáticos, a partir de agora, abriam-se também para revelar e reconhecer as apropriações e ressignificações que as culturas populares, na sua singularidade e criatividade, fazem das propostas de desenvolvimento de organizações governamentais e nãogovernamentais (TAUK SANTOS, 2000).

As culturas populares, compreendidas a partir dos estudos de recepção de MartínBarbero, não são conceituadas por sua autenticidade ou beleza, "mas sim por sua representatividade sociocultural, sua capacidade de materializar e expressar o modo de viver e pensar das classes subalternas [...]" (MARTÍN-BARBERO, 1997, p.105). Este entendimento assume na pesquisa de Extensão Rural em sua relação com o desenvolvimento local, um foco relevante de interesse neste trabalho. Isso porque a dimensão cultural é considerada, por alguns autores, dentro de um complexo multidimensional do desenvolvimento local, isto é, econômico, social, ambiental e político. Jara (1998), por exemplo, traduz essa multidimensionalidade em várias preocupações com: o presente e o futuro; a produção e o consumo de bens e serviços; a necessidade básica de subsistência; os recursos naturais e o equilíbrio ecossistêmico; as práticas decisórias e a distribuirão de poder. Ao tratar da dimensão cultural no desenvolvimento, o autor ressalta que se "deve combinar os interesses com os valores culturais e as decisões com crenças para ativar os processos de inovação" (JARA, 2002, p. 109).
Por sua vez, a noção de sustentabilidade cultural na área do desenvolvimento aparece de modo explícito e chamativo no último parágrafo do livro de Benjamin (2004), Folkcomunicação na Sociedade Contemporânea. Apesar de esta concepção ser ainda pouco explorada nos estudos de desenvolvimento local, salta-se aos olhos como um aspecto significativo no campo da Extensão Rural. O Programa Cultura Viva do Governo Federal, no incentivo e apoio ao Projeto Estação da Cultura: o Ponto de Cultura no Sertão Pernambucano torna-se campo-chave de análise, por reconhecer "a centralidade da dimensão cultural no impulso do desenvolvimento sustentável" (BRASIL, 2004, p. 10), ao auxiliar na formação de jovens agentes culturais, em Arcoverde e nas suas comunidades circunvizinhas.

Nesse sentido, para a Estação da Cultura (2004, p. 4), "Arcoverde é um ponto de encontro", por ser passagem para as comunidades indígenas e remanescentes a quilombolas, estando estrategicamente situada no centro do estado de Pernambuco. Contudo, o poder executivo arcoverdense apóia-se na idéia que essa cidade é de forasteiros, sendo esquecidos os negros e índios, primeiros habitantes dessas localidades, bem como, das comunidades periféricas e rurais. Por isso, o próprio projeto almeja ser o Ponto de Cultura no Sertão pernambucano, numa tentativa de "preservar o patrimônio histórico, ambiental e cultural dessa região" (ASSOCIAÇÃO, 2004, p.4).

O esforço analítico desse trabalho almeja produzir conhecimento sobre a importância da cultura no desenvolvimento local pretendido pela Extensão Rural contemporânea. Isto é, uma proposta de desenvolvimento em bases extensionistas com sustentabilidade cultural. Tem-se, portanto, uma preocupação em construir uma base metodológica, com o objetivo de analisar as possibilidades de sustentabilidade cultural do projeto da Estação da Cultura, vislumbrando nesses agentes culturais como propulsores/extensionistas do desenvolvimento local para Arcoverde.

Em Pernambuco, foram indicados 26 Pontos de Cultura pelo Programa Cultura Viva. Assim, tem-se como objeto de estudo o Projeto Estação da Cultura: o Ponto de Cultura 
no Sertão Pernambucano, em Arcoverde, inicialmente, por ser o primeiro convênio do Ponto de Cultura, assinado no Brasil. No decorrer da pesquisa, outras qualificações da Associação Estação da Cultura foram determinantes: priorizar a idéia de formar agentes culturais, em parceria com a rede escolar, e atuar em comunidades rurais, indígenas e remanescestes de quilombolas; preservar seu espaço físico (um dos poucos locais de Arcoverde com arquitetura conservada, tombada como patrimônio histórico e cultural do estado), e, por fim, agir ativamente no cenário social e político arcoverdense, evidenciado na ocupação da Estação da Cultura, para defender os bens materiais e simbólicos de sua região (ASSOCIAÇÃO, 2004).

Tal afirmação é demonstrada, quando um grupo de atores de teatro decidiu ocupar o prédio da antiga estação ferroviária, em 17 de novembro de 2001, com a intenção de garantir um espaço físico para produção de arte e cultura. Estes atores ainda almejavam preservar seu patrimônio histórico, antes "abandonado e deteriorado". Mas pretendiam, sobretudo, formar lideranças sociopolíticas no Sertão pernambucano: os agentes culturais. Assim, numa atmosfera de conflito e resistência, fundou-se a Associação Estação da Cultura, por meio da união de forças de artistas e pesquisadores, para contrapor as práticas assistencialistas do poder político arcoverdense (ASSOCIAÇÃO, 2004).

A partir da análise do projeto da Estação da Cultura, optou-se por um estudo de caso, além da escolha de instrumentos específicos para coleta de dados. Para isso, são utilizadas as seguintes técnicas: a) levantamento bibliográfico; b) análise documental do projeto original Estação da Cultura: o Ponto de Cultura no Sertão Pernambucano, aprovado pelo Ministério da Cultura; c) realização de roteiros de entrevistas semi-estruturadas, com os agentes culturais articuladores das oficinas artísticas e com os dois membros da Comissão Executiva da Estação da Cultura; e d) observação não participante.

\section{Desenvolvimento local e sustentabili- dade cultural: uma aproximação teórica}

Dentre as concepções sobre desenvolvimento local que contemplam a noção de sustentabilidade, a mais difundida refere-se ao não esgotamento dos recursos naturais que poderão ser necessários a gerações atuais e vindouras. Nesse sentido, o conceito de sustentabilidade relaciona-se com a idéia de preservação e de conservação de recursos naturais limitados e não renováveis, ou seja, aqueles gastos sem uma devida racionalização e podendo escassear numa perspectiva futura. No entanto, pensa-se como Franco (1998), que tal concepção torna-se reducionista, por restringir a noção de sustentabilidade apenas à questão ambiental e ecológica.

A partir desse ponto de vista, o autor afirma que uma organização de um sistema é sustentável, conforme demonstrado na definição do problema de pesquisa, quando se mantém ao longo do tempo, por ter adquirido algumas "características que lhe conferem capacidades autocriativas" (FRANCO, 1998, p.22). Ele ainda afirma que não se pode confundir sustentabilidade com durabilidade. Ressalta que um processo independentemente de ser "econômico, social, cultural, político, institucional ou físico-territorial é sustentável quando se mantém prolongadamente no tempo". Segundo Franco (1998, p. 22) "se um sistema é sustentável, então ele é durável, porque é capaz de se auto-organizar, de se reproduzir, enfim, de autocriar condições para sua continuidade".

Numa discussão sobre ecodesenvolvimento, Sachs (1992) também compreende que a noção de sustentabilidade não se limita apenas à problemática ecológica e ambiental. Tanto que subdivide a idéia de sustentabilidade em cinco dimensões: social, econômica, política, espacial e cultural. Para o autor, a sustentabilidade cultural deve ser analisada no planejamento do desenvolvimento sustentável, por representar um novo paradigma da sustentabilidade. Assegura que seus referenciais metodológicos possibilitam à sociedade acompanhar o ritmo da capacidade dos recursos naturais, com a finalidade de atingir a harmonia entre seres humanos e a natureza. Para isso, constata que a operacionalização da sustentabilidade cultural deve nortear-se na: 
Busca de raízes endógenas dos modelos de modernização e dos sistemas rurais integrados de produção, privilegiando processos de mudança no seio da continuidade cultural e traduzindo o conceito normativo de ecodesenvolvimento em pluralidade de soluções particulares, que respeitem as especificidades de cada ecossistema, de cada cultura, de cada local. (SACHS, 1992, p. 8)

Nesse sentido, o autor parece considerar fundamental, tanto a dimensão cultural no desenvolvimento local sustentável (ao caracterizá-la pela valorização das diferenças, valores e saberes locais de cada população), quanto a ecológica, no seu aspecto imediato e/ ou futuro. Ao definir desenvolvimento sustentável, Costabeber e Caporal (2006), pesquisadores em agroecologia, igualmente classificam em dimensões sociais, culturais e econômicas de uma sociedade, em sintonia com o meio ambiente e com os valores éticos e políticos. A sustentabilidade, para esses autores, deve ser estudada como uma busca incessante de pontos de equilíbrio numa perspectiva multidimensional de uma pirâmide constituída pelas seguintes bases: ecológica, econômica, social (primeiro nível); cultural, política (segundo nível) e ética (terceiro nível). Na ênfase à dimensão cultural, são consideradas as atitudes respeitosas para com a cultura local (os valores, os conhecimentos, os saberes), e ressaltam que esta dimensão deve ser analisada como ponto de partida nos projetos de desenvolvimento.

Apesar da importância da dimensão cultural no desenvolvimento local sustentável, Martinell (2003) diz haver uma carência de pesquisa evidencie a importância e a valorização da dimensão cultural, tanto dos aspectos quantitativos, quanto dos qualitativos. Segundo ele, existe uma dificuldade em atribuir um valor ao retorno das políticas culturais, ou seja, "calcular a rentabilidade social da cultura", enfatizando a necessidade de aferir os benefícios intangíveis das políticas culturais (MARTINELL, 2003, p.97). Deve ser nesse sentido que Canclini (2003, p.37) chama atenção para a necessidade de promover o capital cultural de nossas sociedades, embora diga que "não se trata de acreditar que vamos nos salvar pela cultura. Mas, talvez, nos ocupando das questões culturais consigamos demonstrar que nem tudo depende das dívidas".
Enfatiza-se, ainda, a importância da sustentabilidade cultural, pois na agenda política da maioria dos países, a ação cultural assume o caráter de medida marginal e suplementar, com investimentos precários. Segundo ainda Martinell (2003), a valorização da cultura no setor público é imprescindível para consolidação da democracia, conseqüentemente, promoção do desenvolvimento local. Para o autor, os neoliberais costumam defender que o Estado não deve intervir na cultura, atribuindo-lhe falta de competência. Ainda assegura a necessidade da intercessão do poder executivo, afirmando que ao "deixar a cultura nas mãos do mercado $60 \%$ ou $70 \%$ das formas expressivas desapareceriam" (MARTINELL, 2003, p. 95).

No entanto, Benjamin (2004, p. 139) observa que os próprios órgãos do governo apropriam-se das celebrações tradicionais, sob o patrocínio de grandes empresas, transformando os eventos em espetáculos de massa, definindo como uma "espetacularização da cultura". Do mesmo modo, tal concepção exploradora é denominada por Canclini (1983) de "tecnocratismo desenvolvimentista". O autor explica que a cultura popular é emoldurada aos hábitos estéticos e recreativos do turismo, transformando-a em verdadeiros espetáculos de massas ou em bailes modernos. Afirma que a burguesia comercial insiste em conservar essas festas para expandir seu capital. E, por fim, proporcionar ao homem do campo uma fonte complementar e aos turistas, atrações exóticas.

Dentro desse contexto, Ayala e Ayala (1995) defendem que uma manifestação cultural passa a ser institucional, quando seus produtores são dependentes de patrocínios de uma identidade pública ou privada. Para eles, há uma necessidade de os produtores culturais possuírem poder de decisão, tanto nos componentes estéticos do evento (na dança: coreografia, instrumentária, músicas, versos, falas), quanto nas formas de atuação dos produtores diretos (quem participa, exercendo quais funções). E isso deve ocorrer, não só na apresentação central, mas também, em todas as manifestações adjacentes.

Concordamos com Sousa Santos (2002, p. 49) que, no domínio cultural, os neoliberais são muito seletivos, pois "os fenômenos culturais só lhe interessam na medida em 
que se tornam mercadorias que como tal devem seguir os trilhos da globalização econômica". Para o autor, a resistência mais eficaz contra a globalização hegemônica é a "localização", que reside na promoção das economias locais e comunitárias, diversificadas e auto-sustentáveis e ligadas a forças transnacionais, mas independentes delas. Ainda assegura que, numa cultura cada vez mais desterritorializada, a resposta contra os seus malefícios, seria a descoberta do sentido de lugar e de comunidade.

Desse modo, mencionamos Sousa Santos (2002) por pronunciar a idéia de "globalização contra-hegemônica" na construção de um multiculturalismo emancipatório, baseada no reconhecimento entre identidades e culturas distintas, conforme ele ressalta:

Este reconhecimento pode resultar em múltiplas formas de partilha - tais como, identidades duais, identidades híbridas, interidentidades e transidentidades -mas todas elas devem orientar-se pela seguinte pauta transidentitária e transcultural: temos o direito de sermos iguais quando a diferença nos inferioriza e ser diferentes quando a igualdade nos descaracteriza. (SOUSA SANTOS, 2002 p. 72)

Pensa-se, portanto, que as manifestações culturais não devem estar subordinadas aos ditames de uma elite hegemônica, para evitar justamente uma possível "espetacularização da cultura" ou um desenvolvimento meramente tecnocrático. Nesse sentido, atribui-se a idéia de sustentabilidade como uma questão que faz parte da multidimensionalidade no desenvolvimento local, distante, portanto, do reducionismo econômico no desenvolvimento, bem como, ecológico e ambiental na sustentabilidade. Assim sendo, acredita-se que a sustentabilidade cultural assume um grau de importância na valorização da tradição, dos conhecimentos e dos saberes de uma localidade, mas enfatizando a preocupação com o respeito à diversidade e ao pluralismo cultural, em prol das gerações presentes e futuras.

Dentro dessas preocupações, o Projeto da Estação da Cultura: o Ponto de Cultura no Sertão Pernambucano, selecionado pelo Programa Cultura Viva do Governo Federal, revela-se fecundo, pois parece assimilar o sentido de sustentabilidade cultural, ao deslocar a cultura de uma posição subalterna para estratégica no desenvolvimento, a partir do seu entendimento como usina de símbolos, direito/cidadania e economia. E ainda apresenta-se como "um programa flexível que não será o que o governante pensa ser o certo ou o adequado, mas o que o cidadão consegue tocar adiante"(BRASIL, 2004, p.9). Como também, acolhe a idéia de desenvolvimento sustentável, quando considera que as interações entre o global e o local devem respeitar as ações desenvolvidas em cada Ponto de Cultura. De modo que ganhem musculatura e estrutura óssea, conquistando sua sustentabilidade e emancipação.

O Programa Cultura Viva definiu esse modo de pactuar com a sociedade como "Gestão Compartilhada e Transformadora e envolve os conceitos de empoderamento, autonomia e protagonismo" (BRASIL, 2004, p.20). O Programa enfatiza, assim, a necessidade da ausência de hierarquia na relação entre o Estado e a sociedade civil, considerando-se como uma proposta de construção de uma nova política pública para cultura.

\section{O Ponto de Cultura no Sertão Pernam- bucano: desenvolvimento com sustenta- bilidade cultural}

No seu primeiro edital, publicado no Diário Oficial da União em 16 de julho de 2004, o Ministério da Cultura do Governo Federal, através do Programa Cultura Viva, selecionou 262 projetos e instalações, já existentes no Brasil urbano e rural, para estabelecer seus Pontos de Cultura, com a intenção de ajudar a impulsionar as atividades desses movimentos socioculturais. Para isso, o programa sugeriu algumas idéias, através de cinco ações: Cultura Digital, Agente Cultura Viva, Escola Viva e Griôs, para que os Pontos de Cultura pudessem moldar, adequar ou transfigurar de acordo com sua realidade, disponibilizando ainda equipamentos e recursos (BRASIL, 2004).

No referido projeto, o Ponto de Cultura é o espaço físico da Associação Estação da Cultura, localizada na antiga Estação Ferroviária (RFSA), em Arcoverde. Cada Ponto de Cultura recebeu um total de R\$ 183.493,95, subdivididos em cinco parcelas. Nesse local, de acordo com os idealizadores do programa Cultura Viva, se deu a articu- 
lação entre o Estado e o Ponto da Estação da Cultura (BRASIL, 2004). Na justificativa do Projeto Estação da Cultura: o Ponto de Cultura no Sertão Pernambucano, essa associação define-se "como uma esfera pública que mantém uma relação indissolúvel com as questões de poder e de democracia". Isto se evidencia no seu objetivo geral, aprovado pelo Ministério da Cultura, que é "formar o corpo de agentes culturais aptos para compor a coordenação do Ponto de Cultura e influenciar na proposição das políticas públicas para cultura no Sertão pernambucano" (ASSOCIAÇÃO, 2004).

Na Associação Estação da Cultura, há aproximadamente 120 agentes culturais em processo de qualificação nos Núcleos: Comunicação, Artes Plásticas, Música, Dança/ Capoeira, Teatro, Educação e Pesquisa. Desse total, apenas 33 agentes culturais foram escolhidos para receberem as bolsas da ação "Agente Cultura Viva" do Programa Cultura Viva. O critério de seleção desses jovens deu-se pela idade, entre 16 e 24 anos, e pelo tempo de vínculo com a Estação da Cultura. Tais agentes culturais distribuem-se em 12, no Núcleo de Música, na Rua 18; conhecida como alameda do lixão, periferia de Arcoverde, na Casa da Música; um em Dança/ Capoeira; nove em Teatro, com trabalhos com o Povo indígena Xukuru; quatro em Artes Plásticas, com oficinas na sede da Estação; e sete em Educação e Pesquisa, atuando nos sítios rurais Açudinho e Olho D’água (ASSOCIAÇÃO, 2004).

O Núcleo de Teatro, antes denominado de Artes Cênicas, desenvolve experiências pedagógicas no processo de formação dos agentes culturais, trabalhando com crianças e jovens das comunidades vizinhas da Estação da Cultura, como também, com oficinas com o Povo Xukuru e com Comunidade do Osso, áreas circunvizinhas a Arcoverde. Isto se trata de uma tentativa de estimular a sensibilidade das artes teatrais nesses atores sociais. Seus fundadores ainda consideram o teatro como o pai e mãe da Estação da Cultura (ASSOCIAÇÃO, 2004). No Núcleo de Teatro, encontram-se os trabalhos de maior proeminência da Estação da Cultura, como a oficina Agente Construindo, para qualificação profissional de atores, tendo oito agentes culturais em processo de formação, en- tre 15 a 24 anos. Há também o grupo Troupernas de Pau e Teatro, oficina permanente de equilíbrio e mobilidade em pernasde-pau para montagem da peça "Quadrilha: um romance sertanejo", de Romualdo Freitas. Outro espetáculo em destaque é "Carmem De La Zone", de Sérgio Vieira Cardoso.

A partir do desmembramento do núcleo de Artes Cênicas, também surgiu o Núcleo de Dança, com 11 agentes culturais (de 16 a 24 anos). Seus principais objetivos são fomentar a dança popular em Arcoverde; qualificar bailarinos através da prática e teoria; resgatar a forma autêntica da dança popular da comunidade (Cavalo Marinho, Caboclinhos de Aldeia e os Cocos do Sertão). Essa formação é feita a partir de diversas leituras: Carlos da Fonte, Antonio Nóbrega, Ariano Suassuna, Carlos Milton Junior, como também do conhecimento popular dos mais velhos e ainda de textos extraídos da internet. Tal pesquisa resultou na apresentação da coreografia do Bumba meu Boi do Maranhão.

Por sua vez, o Núcleo de Dança segmenta-se na oficina de Capoeira, com 19 agentes culturais, entre 9 e 23 anos. Os locais das oficinas de capoeira são, além da Estação da Cultura, na aldeia do Povo Xukuru, em Pesqueira, e na Escola Nunes Ferraz, em Arcoverde. Segundo Aldemir (22 anos), articulador da oficina de capoeira, suas pesquisas são fundamentadas "em textos da internet, mas realizamos também entrevistas com capoeiristas de Arcoverde e Juazeiro". Para ele os principais objetivos desta oficina são:

Repassar as técnicas de capoeira para os agentes culturais, com a intenção de que eles multipliquem esse conhecimento para sua comunidade; desmistificar a idéia preconceituosa sobre o conceito de capoeira; formar o agente cultural para vida, através do diálogo e da amizade.

Esse depoimento revela um comprometimento do agente cultural em preservar a fluidez e a agilidade da capoeira, como uma tradição cultural. Observa-se que, através dessas oficinas, pesquisas e entrevistas sobre a capoeira, esses agentes culturais multiplicadores, além de proporcionarem a auto-estima coletiva, poderão possibilitar a continuidade, ou seja, a sustentabilidade cultural de 
uma dança popular que, durante muito tempo, esteve à margem da sociedade.

Com ênfase na musicalidade arcoverdense, o Núcleo de Música, com 11 agentes culturais de 8 a 22 anos, atuando na Casa da Música da Rua 18, periferia de Arcoverde. Esse conhecimento é a proveitado para confecção de instrumentos musicais, como: zabumbas, alfaias, surdos, pífanos e caixas, para serem comercializados. Para Renata (20 anos) e Aldemir (22 anos), articuladores dessas oficinas, o Núcleo de Música tem como objetivos cruciais:

Pesquisar os ritmos locais de Arcoverde; combinar o ritmo erudito com o popular, buscando uma musicalidade original; resgatar a música local, buscando uma visibilidade para sociedade; gerar renda, através da confecção de instrumentos musicais de percussão; integrar música e educação, através de oficinas.

No Núcleo de Música, notamos uma preocupação dos agentes culturais em mesclar os ritmos populares arcoverdenses com a música erudita, numa tentativa de recriar uma musicalidade própria. Na formação desses agentes culturais, parece haver a assimilação da idéia de promoção, preservação e recriação de sua cultura musical, enquanto expressão de uma representação simbólica, além de ressaltar o aspecto econômico, através da comercialização dos instrumentos musicais.

O Núcleo de Artes Plásticas tem como proposta, através de oficinas, a adequação das técnicas das artes plásticas para o público infantil, tendo 16 agentes culturais, entre 10 e 19 anos. O articulador dessas oficinas artísticas, Claudiney Mendes (19 anos), diz que sua finalidade era "constituir um grupo que atuasse e se identificasse com o sentimento da Estação da Cultura". Para isso, almeja "aprimorar o dom artístico de cada agente cultural, descobrindo suas qualidades individuais, para enriquecer com as técnicas das artes plásticas". E ainda pretende "revelar para os agentes culturais o mundo das artes plásticas, para depois apresentar o produto final dessas oficinas para a comunidade". Dentre as exposições já exibidas para sociedade arcoverdense, ele menciona que:

Em 2005, realizamos as exposições Caras e Cores (17 quadros com imagens da Estação da Cultura), Cubando e Expressando o Sertão
(10 quadros retratando o Sertão nordestino, através das técnicas de Picasso do cubismo e expressionismo), e mais 10 quadros com temas livres, sugerido pelos próprios agentes culturais... Em 2006, criamos 20 máscaras de carnaval, nos inspirado num estudo da origem carnavalesca até aos dias atuais. No mesmo ano, no período das festas de São João, os agentes culturais realizaram uma pesquisa teórica de temas juninos universais. Decidimos, então, retratar algo de acordo com a realidade local deles, criando 20 esculturas de personagens do espetáculo Quadrilha: um Romance Sertanejo, uma tradição da Estação da Cultura e de Arcoverde.

A partir desse depoimento, nota-se no Núcleo de Artes Plásticas uma preocupação em potencializar as energias sociais, dando vazão à identificação dos agentes culturais com a própria comunidade arcoverdense. Acredita-se que a exploração da pesquisa da linguagem artística na sua expressão lúdica, além de desenvolver um modo diferenciado de aprendizado, também pode criar um espaço para reflexão crítica sobre a realidade em que o jovem está inserido.

Numa tentativa de discutir a democratização dos meios de comunicação predominantes na região, fundou-se o Núcleo de Comunicação na Estação da Cultura. Suas articuladoras, Emanuelle (17 anos) e Jéssica (16 anos), ressaltam que esse Núcleo tem como objetivos: "informar o público interno da Estação da Cultura, por meio da comunicação interna (mural, panfletos, e-mails e boca a boca)... Atingir o máximo de ouvintes, através dos seus veículos de comunicação". Para isso, o Núcleo de Comunicação desenvolve um programa de rádio semanal sobre a Estação da Cultura, aos sábados de 13 às 14h, na Rádio Aliança, em Arcoverde, em que foram abordados temas como:

Movimento Calango (movimento cultural que ocorreu na década de 80 e 90), no seu primeiro programa no dia 06 de maio de 2006; Povo Negro (13/05); Movimento indigenista, especialmente sobre a morte do Cacique Xicão do Povo Xukuru (20/05); Educação, enfatizando Paulo Freire (27/05); Direito e Segurança (03/06); Universo Feminino (20/ 06); Teatro Popular (17/06); Terra: uma questão fundiária (01/07); Rock (08/07); Sexualidade (15/07); e Religiões (22/07).

Um outro veículo do Núcleo de Comunicação é o jornal mensal Coeviacá. Esta 
expressão é oriunda de uma colagem de vários contos indígenas dos povos do alto Xingu: a Lenda do Píui, cuja história conta a façanha de um índio guerreiro encantado que periodicamente visitava as aldeias ateando fogo nas suas cabanas, com a intenção de reunir as pessoas para sua reconstrução (ASSOCIAÇÃO, 2004). No início da publicação do Coeviacá (já com 8 edições, tendo Teresa Padilha como a jornalista responsável pela sua edição), segundo Emanuelle e Jéssica, os temas desse jornal eram muito centrados nas ideologias e atividades da Estação da Cultura. Assim, elas notaram que esses conteúdos estavam "muitos fechados na Estação". Desde então, decidiram abranger as matérias para temas de interesse da comunidade, especialmente, nas áreas de artes, cultura e política da região.

Segundo Raphaela, articuladora das oficinas artísticas, o Núcleo de Educação e Pesquisa "surgiu após o diagnóstico que no processo de qualificação do agente cultural, há uma necessidade, além da prática, um embasamento teórico, como complementação dessa formação". Desde a ocupação da Estação, as ações em todos os núcleos sempre foram precedidas pela pesquisa, "tanto que para iniciar uma oficina de arte a pessoa precisa se conhecer, por este motivo a primeira ação de um agente cultural é fazer sua história de vida". A importância desse núcleo se revela, na medida em que ele perpassa por todos os núcleos da Estação da Cultura, conforme ela explica:

Em Teatro existe hoje, Encontros Teóricos que acontecem uma vez por mês, onde os atores e atrizes fazem leituras de textos e debatem sobre o que foi pesquisado individualmente dentro de cada temática.... No Núcleo de Artes Plásticas, antes de iniciar qualquer módulo faz-se primeiramente um estudo, por exemplo, antes de aprender as técnicas cubistas, os agentes procuram saber o que é o cubismo, como surgiu e quem foi Pablo Picasso, e assim por diante... Em Dança também não é diferente, como se trabalha principalmente com dança popular é preciso não só aprender os passos, mas saber suas origens... Os capoeiristas estão sempre procurando saber mais, já realizaram pesquisas sobre a história da capoeira além de diversas entrevistas com mestres, instrutores e adeptos desse jogo... A Comunicação é essencialmente educação e pesquisa; desde a relação entre comunicador/a educador/a até a constante busca por novas informações.. O programa de rádio e o jornal exigem a prática cotidiana da pesquisa...

Esse longo depoimento dá sinais evidentes de que o Núcleo de Educação e Pesquisa é eixo motriz das diversas atividades artísticas, aspecto observado, ao longo da apresentação dos Núcleos da Estação da Cultura. Tal núcleo, ainda, é responsável pela manutenção da Biblioteca Paulo Freire, localizada na Estação da Cultura, aberta à comunidade de toda a região. Outra ação deste núcleo é o trabalho dos agentes culturais na Casa da Memória da Vó Chiquinha: eles realizam oficinas de arte e leitura para crianças e desenvolvem pesquisas sobre plantas medicinais, banda de pífano local, bem como, estudos sobre a história da vó Chiquinha e dos objetos desse museu popular. Pensa-se, portanto, que o Projeto Estação da Cultura: o Ponto de Cultura no Sertão Pernambucano, enquanto projeto de intervenção no âmbito da Extensão Rural, pode contribuir para o desenvolvimento com sustentabilidade cultural de Arcoverde. Ao acreditar que as atividades culturais e linguagens artísticas levadas a cabo nessa intervenção, além de exercer um papel fundamental na reintegração social e na reflexão crítica, também são capazes de recuperar a auto-estima e o sentimento de pertencimento comunitário dos habitantes dessas comunidades.

\section{Considerações finais}

Compreende-se, nas questões aqui apresentadas, a importância de centralizar a sustentabilidade cultural no campo da Extensão Rural para o desenvolvimento local. Nesse contexto, compreendemos que a sustentabilidade cultural é uma questão inerente ao complexo multidimensional no desenvolvimento local. Por isso, a idéia do reducionismo econômico, nas teorias desenvolvimentista, bem como ecológico e ambiental, nas concepções sobre sustentabilidade, tornam-se incipientes. Nesse contexto, a noção de sustentabilidade cultural assume um grau de importância na valorização da tradição, dos conhecimentos e dos saberes de uma localidade, ressaltando a preocupação com respeito à diversidade e ao pluralismo 
cultural, em benefício das gerações presentes e vindouras.

O Programa Cultura Viva, através do financiamento do projeto Ponto de Cultura no Sertão Pernambucano, reconheceu as ações da Estação da Cultura, possibilitando, assim, a continuidade na formação dos agentes culturais, em comunidades circundantes à Arcoverde: periféricas, rurais e indígenas. Nessa perspectiva, considera-se a Estação da Cultura, em Arcoverde, como o Ponto amplificador das concepções e ações do projeto da Estação da Cultura, pois sua atuação se expande territorialmente para áreas rurais, como o povoado indígena Xukuru, a comunidade do Osso, em Pesqueira, bem como, os sítios Açudinho e Olhos D’água, em Arcoverde.

De um modo geral, acredita-se que os investimentos do Governo Federal contribuíram para o incremento do Ponto de Cultura da Estação da Cultura. Pois, não se restringiu, apenas, na formação dos agentes culturais, das oficinas Artes Plásticas, Teatro, Dança, Música, Educação e Pesquisa e Comunicação, mas, também, essas oficinas resultaram em produtos para os diversos Núcleos da Estação da Cultura.

Pensa-se, portanto, que o grande desafio do Projeto Estação da Cultura foi designar escassos recursos financeiros e, sobretudo, humanos, para atender a uma extensa área: Arcoverde, o Povo Xukuru, Comunidade do Osso e os sítios Açudinho e Olhos D'água. Dos recursos humanos, apenas duas pessoas adultas, ambas da Comissão Executiva da Estação da Cultura, são as responsáveis por coordenarem e acompanharem a qualificação desses jovens agentes culturais.

Essas reflexões ressaltam a necessidade de centralizar a sustentabilidade cultural, como premissa para o desenvolvimento local. Todavia, mais do que aos agentes culturais importa às comunidades reconhecerem a relevância da dimensão cultural e apropriarem-se dessa noção, com o objetivo de se tornarem protagonistas principais do seu próprio processo de desenvolvimento local. Este trabalho é apenas a ponta de um iceberg, não só a ser conhecido, mas também, lapidado, em busca da construção de um novo olhar sobre a relação entre Extensão Rural e o desenvolvimento com sustentabilidade cultural.

\section{Referências}

ASSOCIAÇ̃̃O Estação da Cultura. Projeto enviado ao MINC, Estação da Cultura: o Ponto de Cultura no Sertão Pernambucano. Arcoverde, 2004.

AYALA, M.; AYALA, M.I.N. Cultura popular no Brasil. São Paulo: Ática, 1995.

BENJAMIN, Roberto. Folkcomunicação na sociedade contemporânea. Porto Alegre: Comissão Gaúcha do Folclore, 2004.

BRASIL, Ministério da Cultura. Programa Nacional de Educação, Cultura e Cidadania - Cultura Viva. BrasíliaDF, 2004.

CALLOU, Angelo Brás Fernandes. Estratégias de comunicação em contextos populares: implicações contemporâneas no desenvolvimento local sustentável. In: CIMADEVILLA, G. (Comp.). Comunicação, tecnologia e desenvolvimento: debates atuais. Rio Cuarto: Córdoba, 2004

CANCLINI, Néstor García. As culturas populares no capitalismo. São Paulo: Brasiliense, 1983.

Reconstruir políticas de inclusão na América latina. In: COELHO, T. (org.). Politicas culturais para o desenvolvimento: uma base de dados para cultura. Brasília: UNESCO Brasil, 2003.

FRANCO, Augusto de. Porque precisamos de desenvolvimento local integrado e sustentável. 2.ed. Brasília-DF: Instituto de Política ,1998.

JARA, Carlos Julio. A sustentabilidade do desenvolvimento local. Brasília-DF: IICA: Recife: Seplan, 1998.

A dimensão intangível do desenvolvimento sustentável. Brasília: IICA, 2001.

MARTÍN-BARBERO, Jesús. Dos meios às mediações: comunicação, cultura e hegemonia. Rio de Janeiro: UFRJ, 1997.

MARTINELL, Alfons. Cultura e cidade: uma aliança para o desenvolvimento. A experiência da Espanha. In: COELHO, T. (org.). Políticas culturais para o desenvolvimento: uma base de dados para cultura. Brasília-DF: UNESCO Brasil, 2003.

SACHS, Ignacy. Ecodesenvolvimento: ecologia e desenvolvimento 1972 -1992. In: MAIMON, Dália (org.). Ecologia e desenvolvimento. Rio de Janeiro: APED, 1992.

SANTOS, Boaventura de Sousa (org.). A globalização e as ciências sociais. São Paulo: Cortez, 2002.

TAUK SANTOS, Maria Salett. Comunicação rural velho objeto, nova abordagem, mediação, reconversão cultural, desenvolvimento local. In: LOPES, M.L.V. de; FRAU-MEIGS; TAUKSANTOS, M.S. (orgs.). Comunicação e informação: identidades sem fronteiras. São Paulo: Intercom; Recife: Bargaço, 2000.

TAUK SANTOS, Maria Salett; CALLOU, Angelo Brás Fernandes. Desafios comunicação rural em tempo de desenvolvimento local. Revista Signo, João Pessoa, ano 2, n. 3, set. 1995. 